\title{
Firm entry, product repositioning and welfare
}

\author{
Eleftherios Zacharias
}

\section{EERI Research Paper Series No 17/2009}

ISSN: 2031-4892

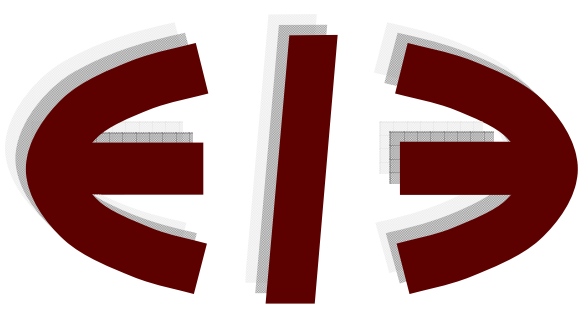

\section{EERI}

Economics and Econometrics Research Institute Avenue de Beaulieu 1160 Brussels

Belgium

Tel: +3222993523

Fax: +322 2993523

www.eeri.eu 


\title{
Firm entry, product repositioning and welfare*
}

\author{
Eleftherios Zacharias \\ Athens University of Economics and Bussiness, \\ 76 Patission Str., 10434 Athens, Greece \\ Rimini Centre for Economic Analysis \\ Email: ezachar@aueb.gr
}

May 7, 2009

\begin{abstract}
We show that the entry of a second firm in a horizontally differentiated market (ala Hotelling) may harm consumers as prices increase and consumer's surplus possibly decrease. We first derive the price and the consumer's surplus of a monopoly which is located at the center of the market. When a second firm enters the market the first firm repositions and the two firms locate at their equilibrium points. Although competition adds to variety and increases consumer's surplus, the post entry increase in price may outweight the gains from extra variety and make consumers worse off.

JEL Classification: L13, D43, D60

Keywords: Horizontal differentiation, welfare analysis, product repositioning
\end{abstract}

\section{Introduction}

We examine the effects of repositioning on prices and consumer's surplus from the entry of a second firm on a horizontally differentiated market. Repositioning may take the form of a change in the physical location where the product is offered: When a second firm decides to sell a differentiated product through a supermarket chain, the incumbent is posible to relocate its product on the shelves of these supermarkets in an effort to minimize the consequences of the entry on its sales. Repositioning may also take the form of relocation in the product space: A number of various reasons such as a change in demographic parameters, demand shocks or mergers may make firms to change the physical characteristics of their products. An example of successful repositioning in the face of competition is the response of MSNBC to Fox News. As Fox Channel

*I would like to thank George Deltas, Paolo Garella and Konstantinos Serfes for their comments. I am responsible for any remaining errors. 
solidified over time its hold of the "right-wing" part of the viewing spectrum, MSNBC repositioned itself as the liberal alternative. Sweeting (2007) estimates the costs and revenues associated with the format switching in the broadcast radio industry. He finds that repositioning raised Hispanic listening by over $20 \%$, as stations entered Spanish-language formats in many markets.

We consider a market in which consumers are located on a Hotelling's line. Post entry, the incumbent which originally is located at the center of the line, relocates and the two firms locate at their equilibrium locations. We show that the entry of a second firm may harm consumers as it may decrease consumer's surplus. We know that competition adds to variety, and thus increases consumer's surplus. On the other hand under certain conditions the duopoly price may exceed the monopoly price. We show that there are parameter values for which the price increase outweights the gains from extra variety and the consumer's surplus decreases. The effect of competition on price is the result of two factors. The demand in duopoly is much steeper than the demand in monopoly: As the monopoly locates at the center of the market, when it lowers its price from the equilibrium price, the quantity demanded increases on both ends of the market. When a duopoly firm unilaterally and marginally lowers its price from the equilibrium level, the demand for its product does not increase on the end point and the number of consumers switching from the other firm is small. Thus, such firm has an incentive to raise its price above the monopoly price. On the other hand, as a duopoly firm sells to fewer consumers its elasticity may be higher than the elasticity of the monopoly. In such case, the duopoly firm has an incentive to set its price below the monopoly price. When the first effect dominates the second, post entry prices increase. The result holds both when post entry the two firms locate within the market quartiles (which occurs when the transportation cost is linear, Hinloopen and van Marrewijk (1999)) and when the two firms locate outside the market quartiles (which occurs when the transportation cost is quadratic, Chrico et. al (2003)).

The increase in prices as the result of intensified competition has been examined in spatial models of product differentiation: Perloff et al. (2005) show that the entry of a second firm in a Hotelling type market will increase the price if the two firms collude and may increase the price if the two firms compete ala Bertrand. Chen and Riordan (2007) analyze a generalized Hotelling model, the spokes model, and show that equilibrium prices can increase with entry. Chen and Riordin (2008) present a general discrete choice model of product differentiation and provide necessary and sufficient conditions for price increasing competition. In the above models, there is no relocation after the entry of the second firm, as in the present paper. Furthermore, here we show that, post entry, consumer's surplus is possible to decrease.

Price increasing competition may hold as a result of imperfect information: When consumers must search for the prices that firms charge, the presence of more firms makes it more difficult to find the lowest price in the market. Consumers' incentives to search reduce and this can cause the equilibrium market price to increase as the number of firms increase (Stiglitz (1987)). In Schultz and Stahl (1996) imperfectly informed consumers search for the best variety. Retail- 
ers locate in the same shopping center. The greater variety of products attracts more customers to the shopping center which might outweight the more intense competition within the shopping center. Here, there is no search as consumers have perfect information.

The result holds in markets with consumers belonging to a loyal group of consumers and a switching group. As the number of sellers increase, the size of the switching group per firm decreases, and its incentive to exploit the captured consumers through a higher price increases. In Rosenthal (1980) the equilibrium prices are in mixed strategies. ${ }^{1}$

This result has also been empirically documented in a number of horizontally and vertically differentiated markets: Goolsbee and Syverson (2006) show that in the passenger airlines industry, competitors of Southwest Airlines raise route prices when Southwest opens new routes to the same destination from a nearby airport. Perloff et al. (2005) show that new entry of differentiated propriated anti-ulcer drugs raises prices in that market. Thomadsen (2007) provides evidence that prices may rise above the monopoly level with entry, in the fast food industry. Furthermore, Caves et al (1991) and Grabowski and Vernon (1992) provide evidence that the price of brand-name drugs in the U.S. increased after the entry of generic drug products. This happens as brand name manufacturers raise their prices to price discriminate when generics enter the market. Ward et al. (2002) show that the entry of private-label food products tend to raise the prices of name-brand products.

In independent work, Cowan and Yin (2008) show that welfare may decrease with competition with the entry of a second firm when transportation cost is linear. They assume that a monopolist is locating at the one end of the Hotelling line, while in duopoly the new firm locates at the other end of the line. Thus, they implicitly assume that there is no option of locating at an interior point within the line. However, Hinloopen and van Marrewijk (1999) show that in this case the equilibrium locations for the two firms will be within the market's quartiles. Here, we consider the equilibrium locations for the two firms with linear and quadratic transportation cost and we compare them with a monopoly that is located at the center of the market space.

\subsection{Linear transportation cost}

We use the standard Hotelling's (1929) duopoly model assuming that consumers have a finite reservation price for the differentiated product as Lerner and Singer (1937). Consumers are located uniformly at the $[0,1]$ interval. For simplicity, we normalize the total number of consumers to one. Each consumer buys one unit of the good. Initially, there is only one firm in the market. The monopoly is located at the center of the characteristic space (as this is the optimal location for the monopoly) and maximizes its profits by setting its price $P_{M}$. In this section we assume linear transportation cost. The utility that a consumer, who is located at point $x$ in the line, gets from buying the product from the monopoly

${ }^{1}$ For a model of a similar flavour, see also Zhou (2006). 
is:

$$
U(x)=V-t\left|x-\frac{1}{2}\right|-P_{M} .
$$

All consumers with nonnegative utility buy from the monopoly.

Post entry, the monopoly relocates and the market can be described by the standard duopoly model. Let now the two firms be $A$ and $B$. Firm $A$ is located at $x_{A}$ and $B$ at $1-x_{B}$. The price each firm sets is $P_{i}$, where $i=A, B$. The utility that a consumer, who is located at point $x$ in the line, gets from buying the product from firm $A$, is:

$$
U_{A}(x)=V-t\left|x-x_{A}\right|-P_{A},
$$

and when he buys from firm $B$ is:

$$
U_{B}(x)=V-t\left|1-x_{B}-x\right|-P_{B} .
$$

A consumer located at $x$ solves:

$$
\max \left\{V-t\left|x-x_{A}\right|-P_{A}, V-t\left|1-x_{B}-x\right|-P_{B}, 0\right\} .
$$

where $t$ is a positive real number which shows the unit transport cost. This specification implies that strong preference for one firm results in strong aversion to the other firm by a factor $t$. $V$ is the reservation price, that is the maximum price that a consumer who is located either at $x_{A}$ or $1-x_{B}$, is willing to pay for the good. Furthermore, to facilitate the analysis we set $\alpha=t / V$. Both firms simultaneously determine where to locate and then simultaneously set their price. Furthermore, the analysis focuses on pure strategy symmetric location equilibria.

It is well known that when $V$ is "high" relative to $t$, there is no pure strategy price-location equilibrium. ${ }^{2}$ For higher values of $\alpha$ we have two types of equilibria. More specifically, for $\frac{8}{7} \leq \alpha<\frac{4}{3}$ Hinloopen and van Marrewijk (1999) show that we have competitive equilibria with full supply. In this case, the distance between the two firms is less than $\frac{1}{2}$. Each firm serves half the market only. Firms charge high prices and as a result the consumers at the endpoints of the product space (at $x=0$ and $x=1$ ) have zero utility. As firms locate within the market's quartiles, the marginal consumer at the center $\left(x=\frac{1}{2}\right)$ of the product space has strictly positive utility. For $\frac{4}{3} \leq \alpha \leq 2$ we have touching equilibria with full supply. In this type of equilibria, the two firms locate at the market's quartiles. Again, each firm covers half the market only. Firms set high prices, so that and the utility of the consumers at $x=0, x=1$ and $x=\frac{1}{2}$ is zero. For $\alpha>2$ the two firms form two local monopolies and do not compete. ${ }^{3}$

We consider values of $\alpha$ for which the optimal price of the monopoly is an interior solution. We derive the price, the consumer's surplus and welfare of the monopoly that, before entry, is located at the center of the product space. We then do the same using the duopoly model for the various parameters of $\alpha$ and

\footnotetext{
${ }^{2}$ In particular this occurs for $\alpha<8 / 7$ (Hinloopen and van Marrewijk (1999)).

${ }^{3}$ This happens when there are consumers who do not buy at all.
} 
the corresponding locations for the two firms. We compare the results in the two models and show that post entry prices can not decrease. Also, there are values of $\alpha$ for which the consumer's surplus is greater before entry. We have the following Lemma.

Lemma 1 With linear transportation cost, the optimal price for the monopoly that is located at $x=\frac{1}{2}$ is an interior solution for $\alpha \geq 1$. All consumers in $\left[\frac{1}{2}-\frac{V}{2 t}, \frac{1}{2}+\frac{V}{2 t}\right]$ buy. The monopoly's price is $\frac{V}{2}$ its profits are $\frac{V^{2}}{2 t}$ the consumer's surplus is $\frac{V^{2}}{4 t}$ and total welfare is $\frac{3 V^{2}}{4 t}$.

When we have two firms and for $\frac{4}{3} \leq \alpha \leq 2$, the price and the total profits are $V-\frac{t}{4}$ the consumer's surplus is $\frac{t}{8}$ and total welfare is $V-\frac{t}{8}$.

When we have two firms and for $\frac{8}{7} \leq \alpha<\frac{4}{3}$, the price and the total profits are $\frac{t}{2}$ the consumer's surplus is $4 V-\frac{2 V^{2}}{t}-\frac{7 t}{4}$ and total welfare is $4 V-\frac{2 V^{2}}{t}-\frac{5 t}{4}$.

The proof is in the Appendix.

From above it is easy to show that post entry: (a) Prices increase ${ }^{4}$ and (b) there are values of $\alpha$ for which competition can harm consumers as total consumer's surplus decreases. We have the following Proposition:

Proposition 2 For linear transportation cost, post entry: Prices increase for $\frac{8}{7} \leq \alpha<2$. Prices remain the same for $\alpha=2$. Consumer's surplus decreases for $\alpha \in\left(\frac{9}{7}, \sqrt{2}\right)$. Consumer's surplus remains the same for $\alpha=\frac{9}{7}$ and $\alpha=\sqrt{2}$.

The proof can be easily derived if we compare the prices and the consumer's surplus in the two models from Lemma 1 for the various values of $\alpha$ and can be found in the Appendix.

We first compare the consumer's surplus of the monopoly with that of the duopoly models when $\frac{8}{7} \leq \alpha<\frac{4}{3}$. Notice that the ratio of the duopoly price over the monopoly price $\frac{t / 2}{V / 2}=\alpha$ increases as $\alpha$ increase. On the other hand, as $\alpha$ increases the monopoly sells to less consumers (the monopoly's market share is $\left.\frac{1}{2}+\frac{V}{2 t}-\left(\frac{1}{2}-\frac{V}{2 t}\right)=\frac{1}{\alpha}\right)$. Recall that in the duopoly model, the two firms always cover the whole market. As $\alpha$ increases, the effect of higher prices dominates the effect of the increased variety on consumer's surplus. As a result, the consumer's surplus is higher in the monopoly model for high values of $\alpha$ (i.e. when $\alpha \in\left(\frac{9}{7}, \frac{4}{3}\right)$ ).

We now compare the consumer's surplus of the monopoly with that of the duopoly models when $\frac{4}{3} \leq \alpha \leq 2$. Here, the ratio of the prices in the two models $\frac{V-\frac{t}{4}}{\frac{V}{2}}=2-\frac{\alpha}{2}$ decreases with $\alpha$. In addition, as $\alpha$ increases, as before, the monopoly sells to less consumers. As a result, the consumer's surplus is higher in the monopoly model for low values of $\alpha$, i.e. when $\alpha \in\left[\frac{4}{3}, \sqrt{2}\right)$.

In Figures 1 and 2 we compare the consumer's surplus when $V=2$. For this $V$ the acceptable values of $t$ in the two models are: $t \in\left[\frac{16}{7}, 4\right]$ in the duopoly model and $t \in[2, \infty)$ in the monopoly model. The two models can be compared

\footnotetext{
${ }^{4}$ The price remains the same when $\alpha=2$.
} 
for $t \in[2,4]$ (recall that the two models can be compared for $\alpha \in[1,2]$ ). For all vales of $t$ the monopoly charges smaller prices (Figure 1). Furthermore, it is clear that there are values of $t$ for which the consumer's surplus is higher in the monopoly model. This happens for $t \in\left(\frac{18}{7}, 2 \sqrt{2}\right)$ (in the AB interval in Figure 2 ). Notice that for these values of $t$ the difference in the prices between the two models (in Figure 1) is high. In Figure 3 we examine the consumer's surplus when $\alpha=\frac{10}{7}$ (with $V=2$ and $t=\frac{20}{7}$ ) for the consumers in $[0,1]$. In such case the monopoly serves only the consumers at the interval $x \in\left[\frac{3}{20}, \frac{17}{20}\right]$ and the consumer's surplus is given by the area (FGK). On the other hand the two firms in the duopoly model serve the whole market and the consumer's surplus is given by the area (CDH) plus the area (HJL). Although (a) all consumers buy in the duopoly model and (b) both the consumers around $x=\frac{1}{4}$ and around $x=\frac{3}{4}$ enjoy a high surplus the total consumer's surplus in the duopoly is smaller than the consumer's surplus in monopoly (the area (EGIH) is greater than the area (CDEF) plus the area (IJLK). This happens as the consumers around $\frac{1}{2}$ enjoy a substantially higher surplus in the monopoly model.

\subsection{Quadratic transportation cost}

We now assume quadratic transportation cost. As before, the monopoly is initially located at the center of the market. ${ }^{5}$ A consumer who buys from the monopoly has utility:

$$
U(x)=V-t\left(x-\frac{1}{2}\right)^{2}-P_{M},
$$

and consumers with nonnegative utility buy from the monopoly.

Post entry, the monopoly relocates and the market can again be described by the standard duopoly model. The utility that a consumer who is located at point $x$ in the line gets from buying the product from $A$ is:

$$
U_{A}(x)=V-t\left(x-x_{A}\right)^{2}-P_{A},
$$

and the utility he gets when he buys from $B$ is:

$$
U_{B}(x)=V-t\left(1-x_{B}-x\right)^{2}-P_{B}
$$

A consumer located at $x$ solves:

$$
\max \left\{V-t\left(x-x_{A}\right)^{2}-P_{A}, V-t\left(1-x_{B}-x\right)^{2}-P_{B}, 0\right\} .
$$

We follow the analysis of Chrico et. al (2003) that give the various equilibrium locations for the two firms. ${ }^{6}$ For $\alpha \in\left[\frac{16}{20}, \frac{16}{9}\right]$ the two firms are located at $x_{A}=\frac{3 \sqrt{t}-2 \sqrt{V+t}}{2 \sqrt{t}}$ and $1-x_{B}=-\frac{1}{2}+\frac{\sqrt{V+t}}{\sqrt{t}}$ and we have a "competitive

\footnotetext{
${ }^{5}$ Notice that again this is the optimal location for the monopoly.

${ }^{6}$ Here, we modify the analysis of Chrico et. al (2003) for general $t$ as in their analysis, they assume $t=1$.
} 
equilibrium with full supply" type of equilibrium. In fact, here, the consumers at the endpoints of the product space enjoy a positive surplus and the consumer at $x=\frac{1}{2}$ does not enjoy a positive surplus. ${ }^{7}$ For $\alpha \in\left[\frac{16}{9}, \frac{16}{3}\right]$ the two firms are located at the two quartiles and we have a touching equilibrium with full supply, in which the consumers at $x=0, x=1$ and $x=\frac{1}{2}$ have zero utility. Finally, for $\alpha>\frac{16}{3}$ the two firms form two (local) monopolies.

We again consider values of $\alpha$ for which the optimal price of the monopoly is an interior solution. This happens for $\alpha \geq \frac{4}{3}$. We follow the analysis of the previous section. We have the following Lemma:

Lemma 3 With quadratic transportation cost, the optimal price for the monopoly that is located at $x=\frac{1}{2}$ is an interior solution for $\alpha \geq \frac{4}{3}$. In such case all consumers in $\left[\frac{1}{2}-\frac{V}{\sqrt{3} \sqrt{t V}}, \frac{1}{2}+\frac{V}{\sqrt{3} \sqrt{t V}}\right]$ buy. The monopoly's price is $\frac{2 V}{3}$ its profits are $\frac{4 V^{2}}{3 \sqrt{3} \sqrt{t V}}$ the consumer's surplus is $\frac{4 V \sqrt{t V}}{9 \sqrt{3} t}$ and total welfare is $\frac{16 V^{2}}{9 \sqrt{3} \sqrt{t V}}$.

When we have two firms and for $\frac{16}{20} \leq \alpha \leq \frac{16}{9}$, the price and the total profits are $-2 t+2 \sqrt{t} \sqrt{V+t}$, the consumer's surplus is $-\frac{1}{2} \sqrt{t}\left(\frac{7 \sqrt{t}}{6}-\sqrt{V+t}\right)$ and total welfare is $-\frac{31 t}{12}+\frac{5}{2} \sqrt{t} \sqrt{V+t}$.

When we have two firms, for $\frac{16}{9} \leq \alpha \leq \frac{16}{3}$ the price and the total profits are $V-\frac{t}{16}$ the consumer's surplus is $\frac{t}{24}$ and total welfare is $V-\frac{t}{48}$.

The proof is in the Appendix. It is easy to prove the following Proposition:

Proposition 4 For quadratic transportation cost post entry: Prices increase for $\frac{4}{3} \leq \alpha<\frac{16}{3}$. Prices remain the same for $\alpha=\frac{16}{3}$. Consumer's surplus decrease for $\frac{4}{3} \leq \alpha<\frac{8 \sqrt[3]{2}}{3}$. Consumer's surplus remains the same for $\alpha=\frac{8 \sqrt[3]{2}}{3}$.

The proof can be easily derived if we compare the prices and the consumer's surplus in the monopoly model with those in the duopoly models for $\frac{16}{12} \leq \alpha \leq \frac{16}{9}$ and $\frac{16}{9} \leq \alpha \leq \frac{16}{3}$ and can be found in the Appendix.

First notice that the monopoly sells only to a $\frac{1}{2}+\frac{V}{\sqrt{3} \sqrt{t V}}-\left(\frac{1}{2}-\frac{V}{\sqrt{3} \sqrt{t V}}\right)=\frac{2}{\sqrt{3 \alpha}}$ mass of consumers around $\frac{1}{2}$. However, the monopoly price is smaller than the price in the duopoly model for both types of equilibria. ${ }^{8}$ Although the consumers who are located around $x_{A}$ and $1-x_{B}$ enjoy a positive surplus this is much smaller than the surplus that enjoy the consumers around the center before entry. For this reason, the consumer surplus is greater in the monopoly, for low values of $\alpha$.

In Figures 4, 5 we compare the consumer's surplus when $V=2$. For this $V$ the acceptable values for $t$ are: $t \in\left[\frac{32}{12}, \frac{32}{2}\right]$ in the duopoly model and $t \in\left[\frac{32}{20}, \infty\right)$ in the monopoly model. As the two models can be compared for $\alpha \in\left[\frac{16}{12}, \frac{16}{3}\right]$ we compare them for $\frac{32}{12} \leq t \leq \frac{32}{3}$. For all vales of $t$ the monopoly charges smaller prices (Figure 4). The consumer's surplus is higher in the monopoly model when $t<\frac{16 \sqrt[3]{2}}{3}$ (in the interval ab in Figure 5). Notice that for these

\footnotetext{
${ }^{7}$ The above hold also for $\alpha \in\left[\frac{16}{33}, \frac{16}{20}\right)$. However, in this range of $\alpha$, the two firms are located outside of $[0,1]$, a possibility that we do not examine.

${ }^{8}$ The price remains the same when $\alpha=\frac{16}{3}$.
} 
values of $t$ the difference between the prices in the two models is high. In Figure 6 we examine the consumer's surplus when $\alpha=\frac{16}{6}$ (with $V=2$ and $t=\frac{32}{6}$ ) for the consumers in $[0,1]$. In such case the monopoly serves only a mass of $\frac{\sqrt{2}}{2}$ consumers around the center of the characteristic space (the consumer's surplus is given by the area $($ edjk $)$ ). On the other hand the two firms in the duopoly model serve the whole market (the consumer's surplus is given by the area (cdh) plus the area (hjl)). Although (a) all consumers buy in the duopoly model and (b) both the consumers around $x=\frac{1}{4}$ and around $x=\frac{3}{4}$ enjoy a high surplus, the total consumer's surplus post entry is smaller (the area ( $\mathrm{dhj}$ ) is greater than the area (cde) plus the area $(\mathrm{kjl})$ ). This happens as the consumers around $\frac{1}{2}$ enjoy a substantially higher surplus in the monopoly model.

\subsection{Appendix}

Proof of Lemma 1:

Proof. First notice that the monopoly maximizes its profits when it is located at $x=\frac{1}{2}$. The monopoly charges price $P_{M}$. All consumers located at $x$ such that $V-t\left|\frac{1}{2}-x\right|-P_{M} \geq 0$ buy from the monopoly. For the marginal consumer who buys from the monopoly and is located at $x<\frac{1}{2}$ we have $x=$ $\frac{2 P_{M}+t-2 V}{2 t}$. Its profits are:

$$
2 P_{M}\left(\frac{1}{2}-\frac{2 P_{M}+t-2 V}{2 t}\right)
$$

The monopoly sets price $P_{M}=\frac{V}{2}$ to maximize its profits. From (1) the monopoly's profits are $\frac{V^{2}}{2 t}$. The consumer at $x=\frac{1}{2}$ has surplus $V-\frac{V}{2}=\frac{V}{2}$. The marginal consumer is located at $x=\frac{1}{2}-\frac{V}{2 t}$. The consumer's surplus is therefore $2\left(\frac{1}{2} \cdot \frac{V}{2} \cdot \frac{V}{2 t}\right)=\frac{V^{2}}{4 t}$ and total welfare is: $\frac{V^{2}}{2 t}+\frac{V^{2}}{4 t}=\frac{3 V^{2}}{4 t}$. Notice that the marginal consumer lies the interval $[0,1]$ for $\alpha \geq 1$.

To analyze the duopoly it suffices to examine firm $A$ as we focus on symmetric equilibria. Also, we do not examine the case where $\alpha \in\left(0, \frac{8}{7}\right)$ as for that range there is no pure strategy symmetric equilibrium in prices and locations. As mentioned above, we do not consider the case where $\alpha \in(2, \infty)$ as for that range the two firms form two local monopolies.

From Hinloopen and van Marrewijk (1999), for $\alpha \in\left[\frac{4}{3}, 2\right]$ we have: $x_{A}=\frac{1}{4}$ and the price $A$ sets is $P_{A}=V-\frac{t}{4}$. As the total market is covered, the total profits for both firms are $V-\frac{t}{4}$. Notice that, firm $A$ sells to all consumers located at $x \leq \frac{1}{2}$. The marginal consumers at $x=0$ and $x=\frac{1}{2}$ are indifferent between buying and not buying. The consumer located at $x_{A}$ has surplus $\frac{t}{4}$. As a result, we have that consumer's surplus is $2\left(\frac{1}{2} \cdot \frac{t}{4} \cdot \frac{1}{2}\right)=\frac{t}{8}$, total profits are $V-\frac{t}{4}$ and total welfare is $V-\frac{t}{4}+\frac{t}{8}=V-\frac{t}{8}$.

From Hinloopen and van Marrewijk (1999), for $\alpha \in\left[\frac{8}{7}, \frac{4}{3}\right)$ we have: $x_{A}=$ $\frac{V}{t}-\frac{1}{2}$ and the price $A$ sets is $P_{A}=\frac{t}{2}$. As the total market is covered, the total profits for both firms are $\frac{t}{2}$. Notice that, firm $A$ sells to all consumers located at $x \leq \frac{1}{2}$. The marginal consumers at $x=0$ is indifferent between buying and not buying. However, the consumer at $x=\frac{1}{2}$, who is indifferent 
from buying from either firm, has surplus $2 V-\frac{3 t}{2}$. The consumer located at $x_{A}$ has surplus $V-\frac{t}{2}$. As a result, we have that consumer's surplus is $2\left(\left(\frac{1}{2} \cdot\left(V-\frac{t}{2}\right) \cdot\left(\frac{V}{t}-\frac{1}{2}\right)\right)+\frac{1}{2}\left(2 V-\frac{3 t}{2}+V-\frac{t}{2}\right) \cdot\left(\frac{1}{2}-\frac{V}{t}+\frac{1}{2}\right)\right)=4 V-\frac{2 V^{2}}{t}-\frac{7 t}{4}$ and total welfare is $4 V-\frac{2 V^{2}}{t}-\frac{5 t}{4}$.

Proof of Proposition 2

Proof. For $\alpha \in\left[\frac{8}{7}, \frac{4}{3}\right)$ the price in the duopoly model is $\frac{t}{2}$ and the price in the monopoly model is $\frac{V}{2}$. As $\alpha=\frac{t}{V}>1$, post entry the price increases.

For $\alpha \in\left[\frac{8}{7}, \frac{4}{3}\right)$ the difference in consumer's surplus between the monopoly and the duopoly models is:

$$
\frac{V^{2}}{4 t}-\left(4 V-\frac{2 V^{2}}{t}-\frac{7 t}{4}\right)=-4 V+\frac{9 V^{2}}{4 t}+\frac{7 t}{4} .
$$

The difference is zero for $t=V$ and $t=\frac{9 V}{7}$. Notice that the difference is positive for $t>\frac{9 V}{7}$ as its derivative with respect to $t$, which is equal to $\frac{7}{4}-\frac{9 V^{2}}{4 t^{2}}$ is positive for $t>\frac{3 V}{\sqrt{7}}$ and $\frac{3 V}{\sqrt{7}}<\frac{9 V}{7}$.

For $\alpha \in\left[\frac{4}{3}, 2\right]$ the price in the duopoly model is $V-\frac{t}{4}$. We have:

$$
V-\frac{t}{4}>\frac{V}{2} \Longrightarrow \frac{V}{2}>\frac{t}{4} \Longrightarrow \alpha<2
$$

post entry the price increases, and only for $\alpha=2$ prices remain the same.

For $\alpha \in\left[\frac{4}{3}, 2\right]$ the difference in consumer's surplus between the monopoly and the duopoly models is:

$$
\frac{V^{2}}{4 t}-\frac{t}{8}
$$

which is positive for $\alpha<\sqrt{2}$, and zero for $\alpha=\sqrt{2}$.

Proof of Lemma 3:

Proof. We now examine the monopoly at $x=\frac{1}{2}$ model. The consumer at $x$ who buys from the monopolist who is located at $x=\frac{1}{2}$ and charges price $P_{M}$ has utility $V-t\left(\frac{1}{2}-x\right)^{2}-P_{M}$. The price $P_{M}$ is such that the marginal consumer who is located at $x^{*}$ has zero surplus. We therefore have: $P_{M}=$ $V-t\left(\frac{1}{2}-x^{*}\right)^{2} \Longrightarrow x^{*}=\frac{1}{2}-\left(\frac{V-P_{M}}{t}\right)^{\frac{1}{2}}$ and $x^{*}=\frac{1}{2}+\left(\frac{V-P_{M}}{t}\right)^{\frac{1}{2}}$. The monopolist who is located at $x=\frac{1}{2}$ maximizes its profits:

$$
2 P_{M}\left(\frac{1}{2}-\left(\frac{1}{2}-\left(\frac{V-P_{M}}{t}\right)^{\frac{1}{2}}\right)\right) \text {. }
$$

From the first order condition we have $P_{M}=\frac{2 V}{3}$. We have $x^{*}=\frac{1}{2}-\frac{V}{\sqrt{3 t V}}$, $x^{*}=\frac{1}{2}+\frac{V}{\sqrt{3 t V}}$. As we require $0 \leq x^{*} \leq 1$ we also require $V \leq \frac{3 t}{4} \Longrightarrow \alpha \geq \frac{4}{3}$. The profits are $\frac{4 V^{2}}{3 \sqrt{3} \sqrt{t V}}$. The consumer located at $x$ who buys from the monopoly has surplus: $V-t\left(\frac{1}{2}-x\right)^{2}-\frac{2 V}{3}$. The consumer's surplus is:

$$
\int_{\frac{1}{2}-\frac{V}{\sqrt{3 t V}}}^{\frac{1}{2}+\frac{V}{\sqrt{3 t V}}}\left(V-t\left(\frac{1}{2}-x\right)^{2}-\frac{2 V}{3}\right) d x=\frac{4 V \sqrt{t V}}{9 \sqrt{3} t},
$$


and total welfare is $\frac{16 V^{2}}{9 \sqrt{3} \sqrt{t V}}$.

Following Chrico et. al (2003), when we have two firms, for $\frac{16}{20} \leq \alpha \leq \frac{16}{9}$ the location of firm $A$ is, $x_{A}=\frac{3 \sqrt{t}-2 \sqrt{V+t}}{2 \sqrt{t}}$ and the location of $B$ is: $1-x_{B}=$ $-\frac{1}{2}+\frac{\sqrt{V+t}}{\sqrt{t}}$. The price and the total profits are $-2 t+2 \sqrt{t} \sqrt{V+t}$. The surplus of a consumer located at $x$ who buys from $A$ is:

$$
\begin{gathered}
V-t\left(x-\left(\frac{3 \sqrt{t}-2 \sqrt{V+t}}{2 \sqrt{t}}\right)\right)^{2}-(-2 t+2 \sqrt{t} \sqrt{V+t})= \\
-\frac{1}{4} \sqrt{t}(-1+2 x)(4 \sqrt{V+t}+\sqrt{t}(-5+2 x)) .
\end{gathered}
$$

The consumer's surplus is:

$$
\begin{aligned}
2 \int_{0}^{\frac{1}{2}}\left(-\frac{1}{4} \sqrt{t}(-1\right. & +2 x)(4 \sqrt{V+t}+\sqrt{t}(-5+2 x))) d x= \\
- & \frac{1}{2} \sqrt{t}\left(\frac{7 \sqrt{t}}{6}-\sqrt{V+t}\right)
\end{aligned}
$$

and total welfare is $-\frac{31 t}{12}+\frac{5}{2} \sqrt{t} \sqrt{V+t}$.

For $\frac{16}{9} \leq \alpha<\frac{16}{3}$ the price and the total profits are $V-\frac{t}{16}$. The consumer located at $x$ and buys form $A$ has surplus

$$
V-t\left(\frac{1}{4}-x\right)^{2}-\left(V-\frac{t}{16}\right)=\frac{1}{2} t(1-2 x) x,
$$

and the total consumer's surplus is

$$
2 \int_{0}^{\frac{1}{2}} \frac{1}{2} t(1-2 x) x d x=\frac{t}{24}
$$

and total welfare is $V-\frac{t}{16}+\frac{t}{24}=V-\frac{t}{48}$.

Proof of Proposition 4.

Proof. For $\frac{16}{12} \leq \alpha \leq \frac{16}{9}$ we first compare the prices in the two models. We have:

$$
-2 t+2 \sqrt{t} \sqrt{V+t}>\frac{2 V}{3} \Longrightarrow 2 \sqrt{t} \sqrt{V+t}>\frac{2 V}{3}+2 t,
$$

and we have:

$$
t(V+t)>\left(\frac{V}{3}+t\right)^{2} \Longrightarrow \frac{t V}{3}>\frac{V^{2}}{9} \Longrightarrow \frac{t}{V}>\frac{1}{3}
$$

which holds as $\frac{16}{12} \leq \alpha$.

We now compare consumer's surplus for the monopoly at $x=\frac{1}{2}$ and the duopoly at $x_{A}=\frac{3 \sqrt{t}-2 \sqrt{V+t}}{2 \sqrt{t}}$ models. The difference in the consumer's surplus is:

$$
\frac{4 V \sqrt{t V}}{9 \sqrt{3} t}-\left(-\frac{1}{2} \sqrt{t}\left(\frac{7 \sqrt{t}}{6}-\sqrt{V+t}\right)\right) .
$$


Its derivative with respect to $V$ is: $\frac{2 V}{3 \sqrt{3} \sqrt{t V}}-\frac{\sqrt{t}}{4 \sqrt{t+V}}$ and is positive in this interval as it is positive for the minimum value of $V$ in the interval, ${ }^{9}$ that is for $V=\frac{9 t}{16}$. We have $\frac{2 V}{3 \sqrt{3} \sqrt{t V}}-\left.\frac{\sqrt{t}}{4 \sqrt{t+V}}\right|_{V=\frac{9 t}{16}}=-\frac{1}{5}+\frac{1}{2 \sqrt{3}}>0$. It therefore suffices to show that the difference is positive for $V=\frac{9 t}{16}$. This holds as for $V=\frac{9 t}{16},(2)$ is equal to $\frac{1}{48}(-2 t+3 \sqrt{3} t)>0$.

For $\frac{16}{9} \leq \alpha \leq \frac{16}{3}$ we first compare the prices in the two models. We have:

$$
V-\frac{t}{16}>\frac{2 V}{3} \Longrightarrow \frac{V}{3}>\frac{t}{16}
$$

which holds as inequality for $\alpha<\frac{16}{3}$ and as equality when $\alpha=\frac{16}{3}$.

We now compare consumer's surplus for the monopoly at $x=\frac{1}{2}$ and the duopoly at the quartiles models. The difference in the consumer's surplus is:

$$
\frac{4 V \sqrt{t V}}{9 \sqrt{3} t}-\frac{t}{24} .
$$

First notice that $\frac{16}{9} \leq \alpha \leq \frac{16}{3} \Longleftrightarrow \frac{3 t}{16} \leq V \leq \frac{9 t}{16}$. The derivative of $\frac{4 V \sqrt{t V}}{9 \sqrt{3} t}$ with respect to $V$ is: $\frac{2 V}{3 \sqrt{3} \sqrt{t V}}$ and is positive. We have:

$$
\frac{4 V \sqrt{t V}}{9 \sqrt{3} t}-\frac{t}{24}=0 \Longrightarrow V=\frac{3 t}{8 \sqrt[3]{2}} .
$$

As $\frac{3 t}{16}<\frac{3 t}{8 \sqrt[3]{2}}<\frac{9 t}{16}$ the difference is negative for $V \in\left[\frac{3 t}{16}, \frac{3 t}{8 \sqrt[3]{2}}\right)$ zero at $\frac{3 t}{8 \sqrt[3]{2}}$ and positive for $\left(\frac{3 t}{8 \sqrt[3]{2}}, \frac{9 t}{16}\right]$. In terms of $\alpha$, the difference is positive for $\alpha \in\left[\frac{16}{9}, \frac{8 \sqrt[3]{2}}{3}\right)$ nd zero at $\alpha=\frac{8 \sqrt[3]{2}}{3}$.

\section{References}

[1] Caves, R., M.D. Whinston, and M.A. Hurwitz (1991), Patent Expiration, Entry, and Competition in the U.S. Pharmaceutical Industry, Brookings Papers in Economic Activity: Microeconomics, 1-48.

[2] Chen, Y., and M.H. Riordan (2007), Price and Variety in the Spokes Model, Economic Journal, 117, 897-921.

[3] Chen, Y., and M. H. Riordan (2008), Price increasing competition, RAND Journal of Economics, 39, 1042-1058.

[4] Chrico, A., Lambertini, L., and F. Zagonari (2003), How demand affects optimal prices and product differentiation, Papers in Regional Science, 82, 555-568.

\footnotetext{
${ }^{9}$ We have: $\frac{16}{12} \leq \alpha \leq \frac{16}{9} \Longleftrightarrow \frac{9 t}{16} \leq V \leq \frac{12 t}{16}$.
} 
[5] Cowan, S., and Yin, X. (2008), Competition can harm consumers, Australian Economic Papers, 47, 3, 264-271.

[6] Goolsbee, A., and C., Syverson (2006), How do incumbents respond to the threat of entry: Evidence from major airlines, University of Chicago, working paper.

[7] Grabowski, H. G., and J. M. Vernon (1992), Brand loyalty, entry and price competition in pharmaceuticals after the 1984 Drug Act, Journal of Law and Economics, 35: 331-350.

[8] Hinloopen, J., and C., van Marrewijk (1999), On the limits of the principle of minimum differentiation, International Journal of Industrial Organization, 17, 735-750.

[9] Hotelling, H. (1929), Stability in competition, Economic Journal, 41-57.

[10] Lerner, A.P., and H.W. Singer (1937), Some notes on duopoly and spatial competition, Journal of Political Economy, 45, 145-186.

[11] Perloff, J.M., V.Y., Suslow and P.J., Seguin (2005), Higher prices from entry: Pricing of brand-name drugs, mimeo.

[12] Rosenthal, R.W. (1980), A model in which an increase in the number of sellers leads to a higher price, Econometrica, 48, 1575-1580.

[13] Schulz, N., and K. Stahl (1996), Do Consumers Search for the Higher Price? Oligopoly Equilibrium and Monopoly Optimum in Differentiated-Products Markets. Rand Journal of Economics, 27, 542-562.

[14] Sweeting, A. (2007), Dynamic product repositioning in differentiated product markets: The case of format switching in the commercial radio industry, NBER working paper 13522.

[15] Stiglitz, J.E. (1987), Competition and the Number of Firms in a Market: Are Duopolists More Competitive Than Atomistic Markets?, Journal of Political Economy, 95: 1041-1061.

[16] Thomadsen, R. (2007), Product positioning and competition: The role of location in the fast food industry, Marketing Science, 26, 792-804.

[17] Ward, M,R., J.P. Shimshack, J.M. Perloff, and Harris, J.M. (2002), Effects of the private-label invasion in food industries, American Journal of Agricultural Economics, 84, 961-973.

[18] Zhou, W. (2006), A simple model of entry that increases price levels and price dispersion, Advances in Economic Analysis and Policy, 6, 1, Article 7 . 

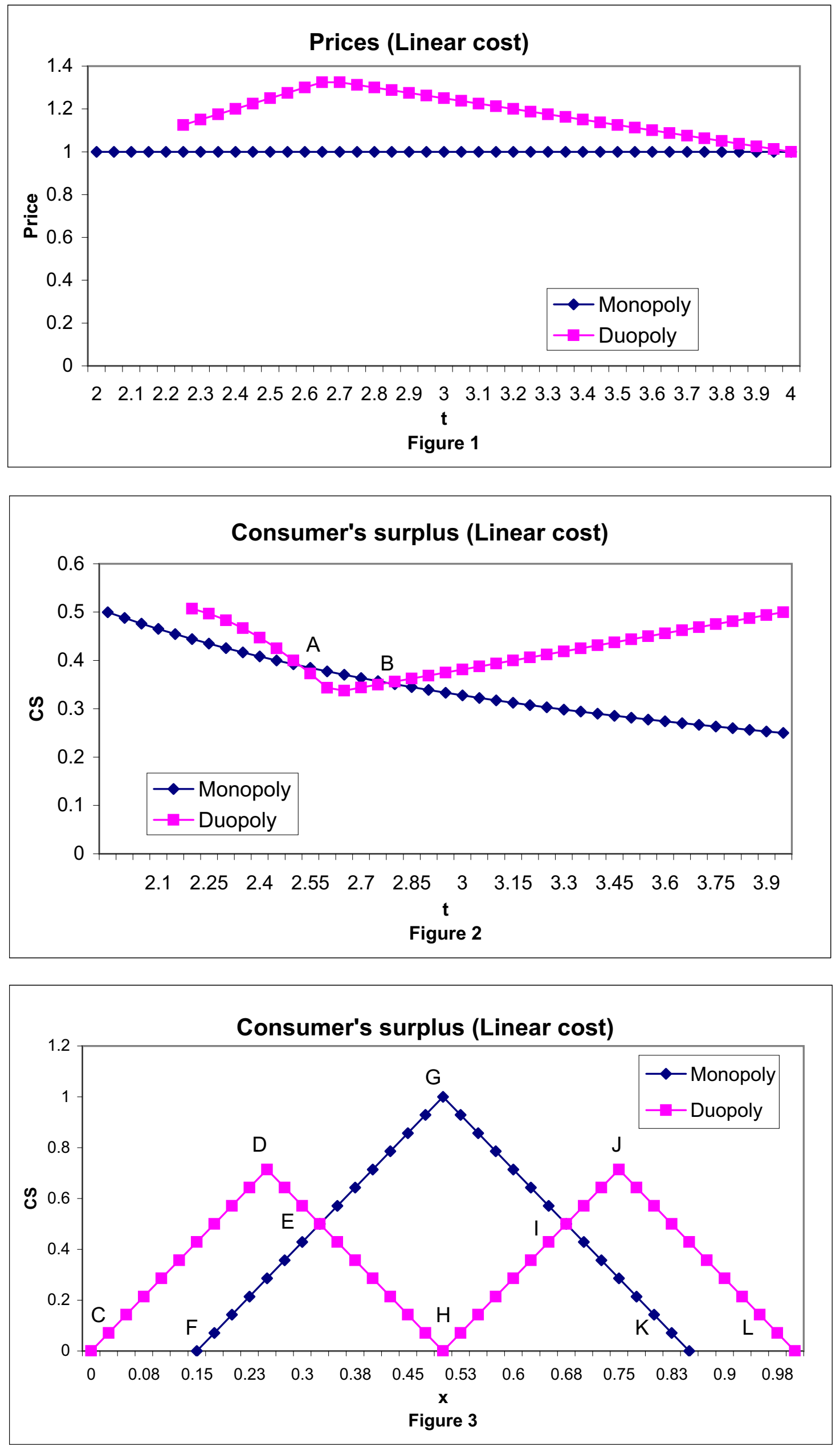

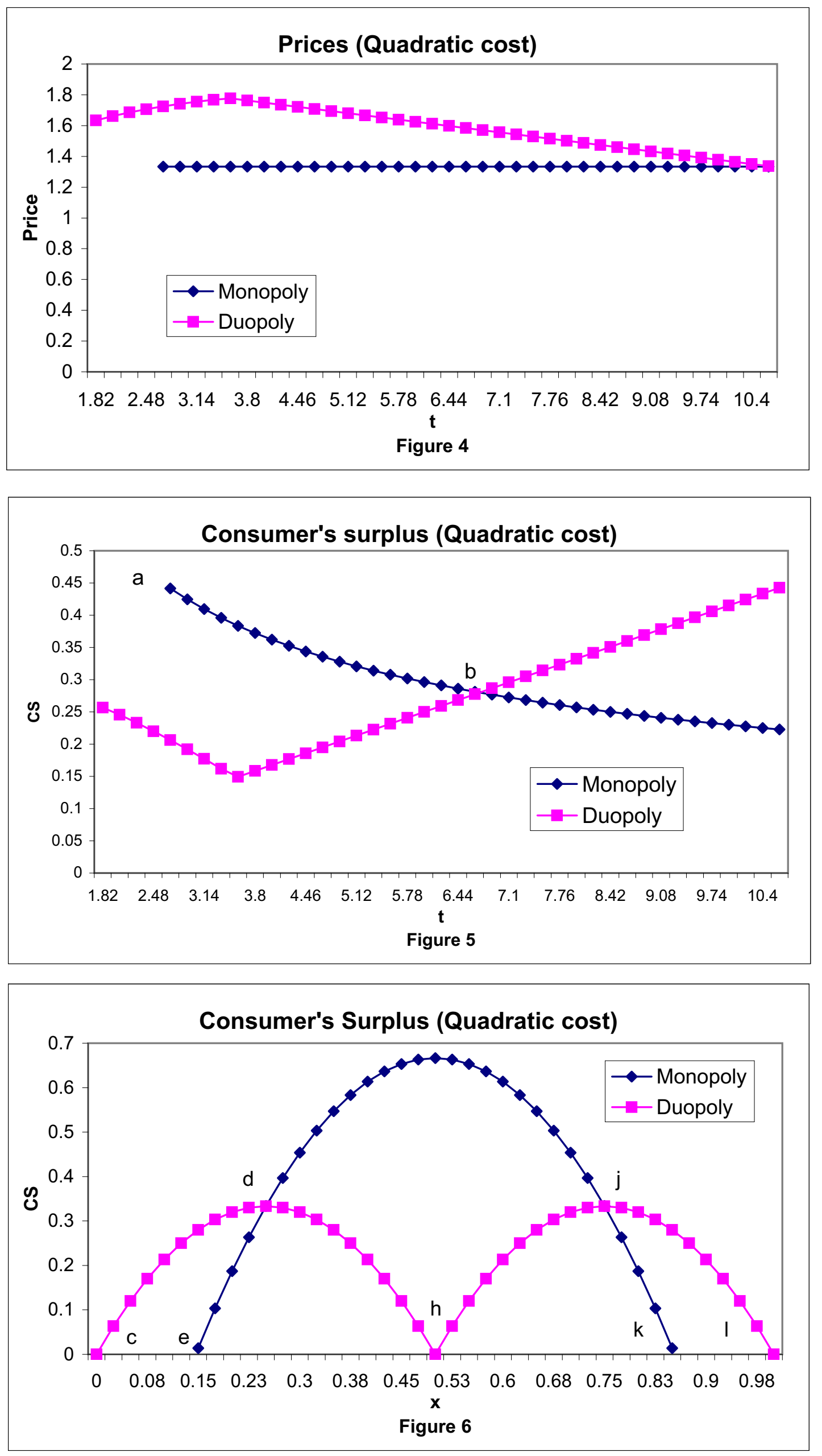